
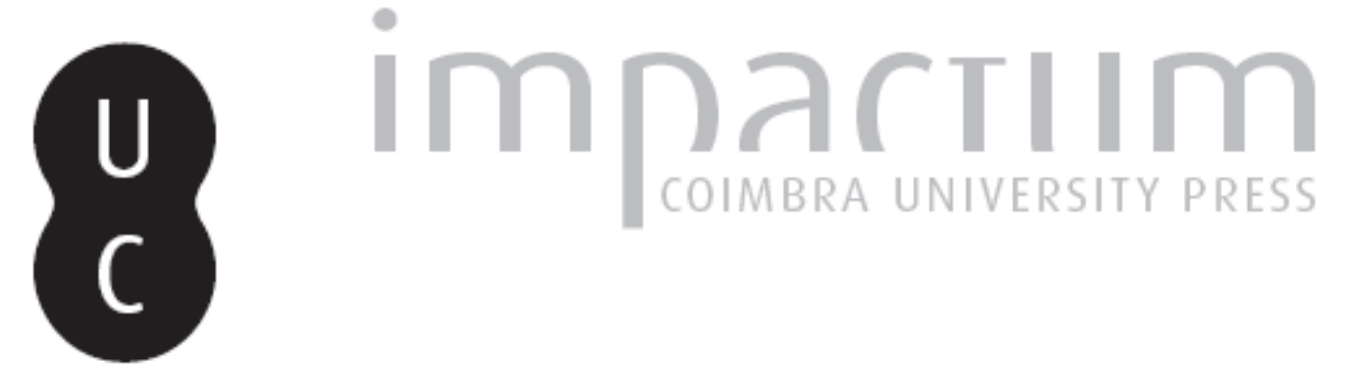

\title{
A comunidade portuguesa de Macau: integração e (re)construção identitária na história recente
}

Autor(es): $\quad$ Branco, Inês

Publicado por: Imprensa da Universidade de Coimbra

URL persistente:

URI:http://hdl.handle.net/10316.2/43242

DOI:

DOI:https://doi.org/10.14195/0870-4147_48_6

Accessed : $\quad$ 26-Apr-2023 12:13:01

A navegação consulta e descarregamento dos títulos inseridos nas Bibliotecas Digitais UC Digitalis, UC Pombalina e UC Impactum, pressupõem a aceitação plena e sem reservas dos Termos e Condições de Uso destas Bibliotecas Digitais, disponíveis em https://digitalis.uc.pt/pt-pt/termos.

Conforme exposto nos referidos Termos e Condições de Uso, o descarregamento de títulos de acesso restrito requer uma licença válida de autorização devendo o utilizador aceder ao(s) documento(s) a partir de um endereço de IP da instituição detentora da supramencionada licença.

Ao utilizador é apenas permitido o descarregamento para uso pessoal, pelo que o emprego do(s) título(s) descarregado(s) para outro fim, designadamente comercial, carece de autorização do respetivo autor ou editor da obra.

Na medida em que todas as obras da UC Digitalis se encontram protegidas pelo Código do Direito de Autor e Direitos Conexos e demais legislação aplicável, toda a cópia, parcial ou total, deste documento, nos casos em que é legalmente admitida, deverá conter ou fazer-se acompanhar por este aviso.

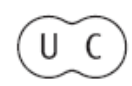




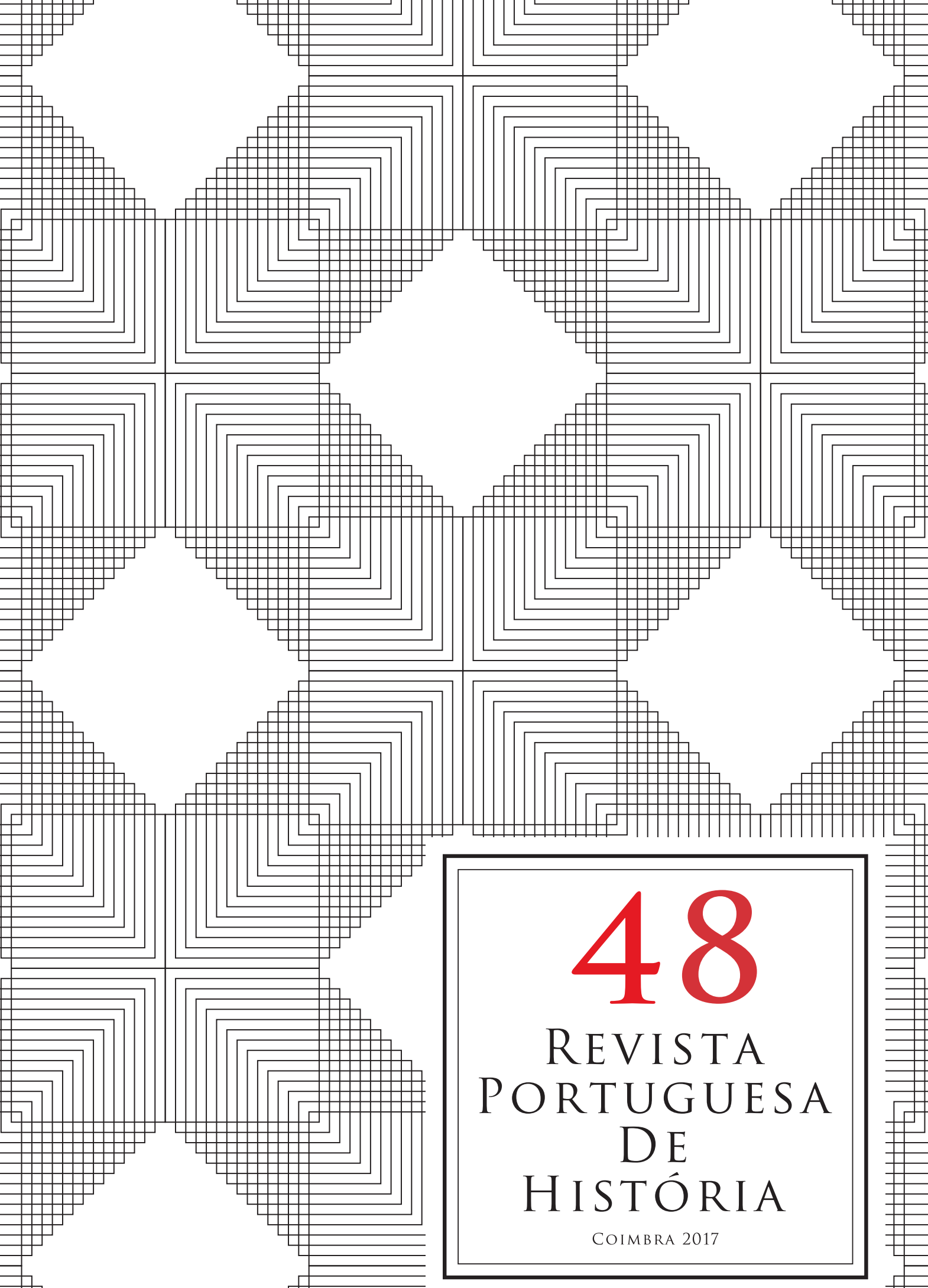




\title{
A comunidade portuguesa de Macau: integração e (re)construção identitária na história recente
}

\author{
The Portuguese community of Macao: \\ integration and identity (re)construction in recent history
}

\author{
INÊS BRANCO \\ FLUC/DLLC - Departamento de Línguas, Literaturas e Culturas \\ branco.ines@gmail.com
}

Texto recebido em/Text submitted on: 30/01/2017

Texto aprovado em/Text approved on: 08/06/2017

\section{Resumo:}

Este artigo tem como foco a comunidade portuguesa de Macau e procura perceber como se integra atualmente na região, tendo em conta dois acontecimentos marcantes na história recente. Um, na região de acolhimento - a entrega do território à República Popular da China, em 1999; outro, no país de origem - a crise económica iniciada em 2008. Recorrendo a 24 entrevistas em profundidade com posterior análise de conteúdo, o objetivo é fazer, por um lado, uma reflexão sobre o processo migratório que leva novos imigrantes a Macau e que faz regressar ao território outros que já ali tinham vivido. Por outro, entender como se redefine identitariamente uma comunidade em mudança num território que procura, também ele, uma nova identidade.

Palavras-chave:

Emigração portuguesa; identidade; Macau.

\section{Abstract:}

This article is based on an investigation carried out in the Portuguese community of Macao, which sought to understand how it is currently integrated in the region, considering two major events in recent history. One in the host region - the handover in 1999; another in the country of origin - the economic crisis that began in 2008. Using 24 in-depth interviews and subsequent content analysis, our objective was to reflect on the migration process that brings new immigrants to Macao and that brings back to the territory others who had already lived there; and to understand how a changing community is redefined in a territory that also seeks a new identity.

\section{Keywords:}

Portuguese emigration; identity; Macao. 


\section{Introdução}

A história recente da imigração em Portugal começa na década de setenta. Até então, era um país, essencialmente, de emigração. Devido à saída de cidadãos nacionais, nomeadamente com destino à Europa e às então províncias ultramarinas, os fluxos migratórios em Portugal registavam um saldo claramente negativo. Este fenómeno alterou-se profundamente com a revolução de 25 de Abril de 1974 e com a subsequente independência dos atuais países africanos de língua oficial portuguesa (PALOP). Segundo Baganha ${ }^{1}$, o fim do império colonial português provocou o retorno a Portugal de meio milhão de nacionais, dos quais 59 por cento tinham nascido na metrópole. Os restantes incluíam os seus descendentes, bem como pessoas de naturalidade e ancestralidade africana de nacionalidade portuguesa.

Em 1986, com a entrada de Portugal para a Comunidade Económica Europeia (CEE) e com os investimentos em construção de infraestruturas que desde então se verificaram, as oportunidades de trabalho indiferenciado fizeram crescer o mercado de emprego. Estas oportunidades vieram atrair um número crescente de familiares e conterrâneos africanos que tinham permanecido nos seus países após a independência. Como o meio de entrada legal mais expedito e eficaz era o recurso aos vistos de curta duração, isto fez com que um número crescente de imigrantes dos PALOP sem autorizações de residência se radicasse em território nacional, em especial na área metropolitana de Lisboa. Ou seja, formou-se uma bolsa de clandestinos que, desde meados dos anos oitenta, cresceu ininterruptamente e cuja presença era tanto do conhecimento público como das autoridades competentes ${ }^{2}$.

Os anos noventa caracterizam-se pela consolidação e crescimento da população estrangeira residente, com destaque para as comunidades oriundas dos países africanos de expressão portuguesa, do Brasil, que estava a braços com uma crise económica que vinha já dos anos oitenta, e dos países de Leste, pois com a entrada em vigor, em março de 1995, da Convenção da Aplicação de Schengen, deixou de ser necessária a consulta prévia para a concessão de visto aos nacionais da Rússia, Ucrânia, Roménia e outros países do Leste europeu ${ }^{3}$.

\footnotetext{
${ }^{1}$ Maria Ioannis Baganha, "Política de imigração: A regulação dos fluxos." Revista Crítica de Ciências Sociais, 2005, p. 31.

${ }^{2}$ Idem.

${ }^{3}$ Maria Ioannis Baganha, "Política de imigração: A regulação dos fluxos." Revista Crítica de Ciências Sociais, 2005, p. 33.
} 
No século XXI, segundo o $\mathrm{SEF}^{4}$, desde a segunda metade da primeira década, a tendência relativamente ao fluxo imigratório alterou-se, com a entrada de menos estrangeiros em Portugal. Os novos fluxos do Leste europeu assumiram um súbito e inesperado destaque, em especial os oriundos da Ucrânia, país que rapidamente se tornou numa das comunidades estrangeiras mais representativas.

A partir de 2008, o pendor do saldo migratório português sofreu variações substanciais. Se em 2009, o número da população estrangeira residente em Portugal era de 459.191 pessoas, em 2015 era de apenas 388.731, vindo sempre a decrescer neste intervalo de tempo ${ }^{5}$. Quanto à emigração, em 2005, o número total de emigrantes portugueses era 1.936.066, crescendo para 2.098.897, em 2010 , e, em 2015, era de $2.306 .321^{6}$. Os principais fatores explicativos desta inflexão estão relacionados com o aumento do acesso à nacionalidade portuguesa (ao abrigo da atual Lei da Nacionalidade) por parte de estrangeiros residentes, a alteração dos processos migratórios em alguns países de origem (nomeadamente Brasil e Angola) e os efeitos da atual crise económica e financeira no mercado laboral, que se traduziu numa redução do investimento e do emprego ${ }^{7}$. O início da crise económica em Portugal fez com que muitos portugueses se voltassem para o resto do mundo e decidissem emigrar. Macau foi um dos destinos.

Com base nesta conjuntura, este artigo tem como foco a comunidade portuguesa de Macau, com passaporte português, que nasceu em Portugal e que migrou. Tendo sido feita em Macau, com recurso a entrevistas em profundidade, analisamo-la da perspetiva da sociedade de acolhimento.

\section{Imigrantes portugueses em Macau}

Mais de quinhentos anos passaram sobre a chegada dos portugueses à China, em 1513. Macau era então uma península abrigada e ponto de paragem de navegadores.

${ }^{4}$ SEF. Relatório de Imigração, Fronteiras e Asilo, 2011. Lisboa: Serviço de Estrangeiros e Fronterias, 2012, p. 15.

${ }^{5}$ SEFSTAT - Portal de Estatísticas do Serviço de Estrangeiros e Fronteiras (https://sefstat. sef.pt/distritos.aspx, consultado em 2017.06.13).

${ }^{6}$ Observatório da Emigração (http://observatorioemigracao.pt/np4/1315/, consultado em 2017.01.27)

${ }^{7}$ SEF. Relatório de Imigração, Fronteiras e Asilo, 2013. Lisboa: Serviço de Estrangeiros e Fronteiras, 2014, p. 10. 
"Em 1553, invocando o pretexto de secar mercadorias alagadas, os portugueses obtiveram autorização das autoridades chinesas locais para permanecerem temporariamente na península de Macau e fazerem comércio, mediante o pagamento de um foro ao Governo chinês, prática que teve início por alturas de $1573^{\prime \prime}$.

A Região Administrativa Especial de Macau (RAEM) situa-se no sudeste da China, a oeste do delta do Rio das Pérolas, a 60 quilómetros de Hong Kong e a 145 quilómetros de Cantão, ou Guangzhou, capital da província com o mesmo nome, Cantão, ou em cantonês Guangdong9 .

\section{Mapa 1 - Localização geográfica de Macau}

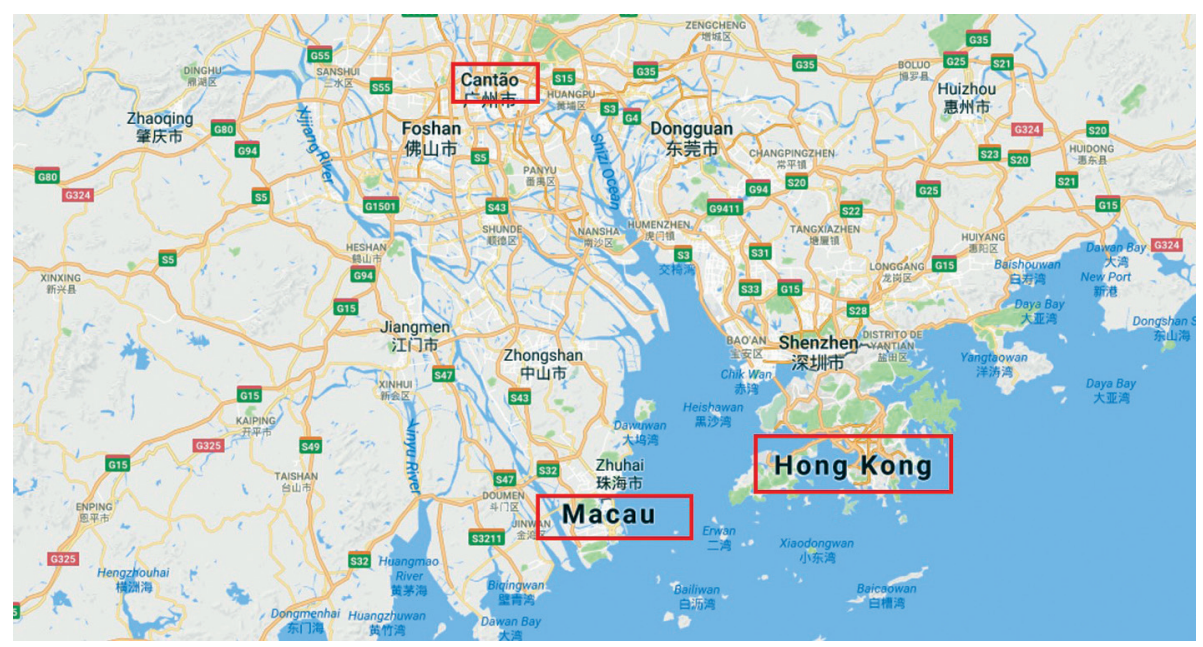

Fonte: Google Maps.

Com uma área de 11,6 quilómetros quadrados no século XIX, o território ocupa atualmente um total de 31,3 quilómetros quadrados, incluindo as ilhas da Taipa e de Coloane. Tal aumento deve-se a aterros feitos na orla marítima, que expandiram a área da península e ligaram a Taipa a Coloane. A norte, a península de Macau está ligada à China continental, fazendo fronteira com a

${ }^{8}$ Gabinete de Comunicação Social do Governo da RAEM, "Macau 2016 - Livro do Ano", p. 528 (http://yearbook.gcs.gov.mo/uploads/yearbook_pdf/2016/myb2016pPA01CH25.pdf, consultado em 2017.30.01)

${ }^{9}$ Gabinete de Comunicação Social do Governo da RAEM, "Geografia e População" (http:// www.gcs.gov.mo/files/factsheet/geography.php?PageLang=P, consultado em 2017.01.30) 
cidade de Zhuhai, através das Portas do Cerco. A construção inicial, com a data de agosto de 1849 ainda existe, mas já tem por detrás o novo posto fronteiriço, construído em $2004^{10}$.

Em dezembro de 2015, a região de Macau tinha 646.800 habitantes e uma densidade demográfica de 21.100 habitantes por quilómetro quadrado. O movimento de entradas na RAEM (visitantes) registou também um número impressionante, com um total de quase 31 milhões de turistas num ano ${ }^{11}$.

Os homens representam 49 por cento da população residente e as mulheres 51 por cento. 92,3 por cento da população é de ascendência chinesa, 0,9 por cento de ascendência portuguesa e 2,7 por cento de ascendência filipina. A ascendência relaciona-se com a nacionalidade, o que não quer dizer que seja população nascida obrigatoriamente nos países de origem. No caso dos portugueses, existe uma parte da população que nasceu em Macau durante a administração portuguesa e optou pela nacionalidade portuguesa em vez da nacionalidade chinesa. Se contarmos apenas os portugueses nascidos em Portugal são apenas 0,3 por cento da população ${ }^{12}$.

Quinze anos após a transferência de Macau para a República Popular da China, o território procura ser hoje uma ponte entre a China e o mundo lusófono:

"O território retornou à mãe-pátria, mas manteve as suas especificidades lusófonas, um peão embrenhado num jogo de sombras chinesas para alcançar interesses além-mar. Oficialmente designado como plataforma de ligação da China ao mundo lusófono, Macau refugia-se no papel de intermediário que os seus contornos únicos lhe permitem desempenhar."13

Macau nunca foi uma colónia, mas sim um território sob administração portuguesa, um caso de soberania partilhada, nunca tendo sido contemplado pela vaga da descolonização, sendo antes sujeito a um processo de retrocessão, resolvido pela via negocial. Ou seja, foi absorvido pelo país ao qual pertencia antes de ser administrado pela potência colonial, tal como Goa.

${ }^{10}$ Idem.

${ }^{11}$ Gabinete de Comunicação Social do Governo da RAEM, "Macau 2016 - Livro do Ano", p.8 (http://yearbook.gcs.gov.mo/uploads/yearbook_pdf/2016/myb2016pPA01CH25.pdf, consultado em 2017.30.01)

${ }^{12} \mathrm{Idem}$.

${ }^{13}$ Carmen Mendes, "Macau 500 Anos Depois: A Plataforma da China para o Mundo Lusófono", Revista Oriente, 22 (2013), p. 44-59. 
“A acta das conversações sobre a questão de Macau, assinada em 1979 aquando do restabelecimento de relações diplomáticas luso-chinesas, já dizia que o território sob administração portuguesa seria «restituído à China (...), no momento julgado oportuno pelos governos dos dois países e por meio de negociações». Tal viria a acontecer no rescaldo das negociações sino-britânicas sobre Hong Kong, resultando na assinatura da Declaração Conjunta de Macau em 1987, que estipulou a transferência da administração portuguesa para a República Popular da China (RPC) em 1999.”14

Em 1999 foi criada a Região Administrativa Especial de Macau (RAEM), que abrange a península de Macau e as ilhas da Taipa e de Coloane, administrada de acordo com o princípio "um país, dois sistemas", consagrado na Lei Básica da Região Administrativa Especial de Macau ${ }^{15}$, uma espécie de constituição. Pode ler-se no preâmbulo:

"A fim de salvaguardar a unidade nacional e a integridade territorial, bem como favorecer a estabilidade social e o desenvolvimento económico de Macau, tendo em conta o seu passado e as suas realidades, o Estado decide que, ao voltar a assumir o exercício da soberania sobre Macau, cria-se a Região Administrativa Especial de Macau de acordo com as disposições do artigo 31. ${ }^{\circ}$ da Constituição da República Popular da China e que, de harmonia com o princípio «um país, dois sistemas», não se aplicam em Macau o sistema e as políticas socialistas. As políticas fundamentais que o Estado aplica em relação a Macau são as já expostas pelo Governo Chinês na Declaração Conjunta Sino-Portuguesa.

De harmonia com a Constituição da República Popular da China, a Assembleia Popular Nacional decreta a Lei Básica da Região Administrativa Especial de Macau da República Popular da China, definindo o sistema a aplicar na Região Administrativa Especial de Macau, com vista a assegurar a aplicação das políticas fundamentais do Estado em relação a Macau."16

De acordo com os artigos $2 .^{\circ}$ e $5 .^{\circ}$ da Lei Básica, a China autoriza a RAEM a exercer um alto grau de autonomia e a gozar de poderes executivo, legislativo e judicial independentes, incluindo o de julgamento em última instância, mantendo-se inalterados durante cinquenta anos o sistema capitalista e a maneira

${ }^{14}$ Carmen Mendes, "Macau 500 Anos Depois...”, cit., p. 44.

${ }^{15}$ Governo da RAEM, Imprensa Oficial, "Lei Básica da Região Administrativa Especial de Macau da República Popular da China” (http://bo.io.gov.mo/bo/I/1999/leibasica/index.asp, consultado em 2017.01.30)

${ }^{16}$ Idem. 
de viver anteriormente existentes. Pelo mesmo período a língua portuguesa é língua oficial em simultâneo com o mandarim, segundo o artigo 9.'.

"Além da língua chinesa, pode usar-se também a língua portuguesa nos órgãos executivo, legislativo e judiciais da Região Administrativa Especial de Macau, sendo também o português língua oficial." ${ }^{17}$

\section{Comunidade portuguesa de Macau}

A existência da comunidade portuguesa em Macau remonta ao século XVI. Desde então, como refere João Pina Cabral em "A complexidade étnica de Macau" 18 , Macau tem sido coisas muito diferentes, mas uma permaneceu ao longo do tempo - "a confrontação de uma pequena, mas contumaz população de cristãos, súbditos do Rei de Portugal, com o espírito plástico e criativo do povo cantonense". Ainda nos anos 90, o investigador referia as muitas mudanças que tinham ocorrido nas duas décadas anteriores no território, que surgia "perante os nossos próprios olhos como uma nova cidade", e previa que as que se seguiriam nas décadas futuras fossem "pelo menos tão profundas quanto as que pudemos observar até hoje". Estava certo.

Quanto à sociedade de Macau, Pina Cabral ${ }^{19}$ identificava três categorias étnicas, que tendiam a estruturar-se em torno de duas línguas, o português e o cantonês - os portugueses, os macaenses e os chineses. Como veremos mais à frente, nos resultados do estudo, a estrutura hoje é mais complexa, acrescentando-se uma outra língua que cada vez ganha mais poder em Macau, a língua oficial de toda a China, o mandarim. Por outro lado, a comunidade macaense tem vindo a perder importância e é cada vez mais um resquício histórico.

Nas duas últimas décadas do século XX, a comunidade portuguesa de Macau integrava, sobretudo, o aparelho administrativo e tendia a viver no território por curto período de tempo.

"A grande maioria destas pessoas passa poucos anos em Macau. Alguns deles, porém, criam laços no Território, estabelecendo-se de forma permanente. Neste último caso, trata-se geralmente de pessoas que se encontram em profissões liberais e que se casam com macaenses ou chineses de Macau". ${ }^{20}$

\footnotetext{
${ }^{17}$ Idem.

${ }^{18}$ Cabral, João de Pina. “A complexidade étnica de Macau.” Revista de Cultura, 1994.

${ }^{19} \mathrm{Idem}$.

${ }^{20}$ Idem.
} 
O número de portugueses que se deslocaram para Macau neste período não é, no entanto, preciso. Segundo a investigadora Inês Costa Pessoa ${ }^{21}$, uma das dificuldades no apuramento dos valores era a nacionalidade, já que uma parte da população chinesa natural de Macau optava pela nacionalidade portuguesa. Hoje, este dado é contemplado nas estatísticas. No nosso estudo incluímos apenas os portugueses nascidos em Portugal.

Segundo os dados do Observatório da Emigração (OE) português ${ }^{22}$, em 2011, nascidas em Portugal existiam 1.835 pessoas ( 0,3 por cento da população de Macau). Com nacionalidade portuguesa, o que não implica terem migrado ou nascido em Portugal, existiam 5.020 pessoas $(0,9$ por cento da população de Macau).

Como se pode observar no quadro 1 , o número de estrangeiros nascidos em Portugal, ou seja, de imigrantes portugueses, na perspetiva de Macau, teve uma queda entre 1996 e 2006. A partir de 2006 começou novamente a aumentar.

\section{Quadro 1 - Evolução da População residente em Macau, 1991-2011}

\begin{tabular}{|l|r|r|r|r|r|}
\hline & \multicolumn{1}{c|}{$\mathbf{1 9 9 1}$} & \multicolumn{1}{c|}{$\mathbf{1 9 9 6}$} & \multicolumn{1}{c|}{$\mathbf{2 0 0 1}$} & \multicolumn{1}{c|}{$\mathbf{2 0 0 6}$} & \multicolumn{1}{c|}{$\mathbf{2 0 1 1}$} \\
\hline População total & 355.693 & 414.128 & 435.235 & 502.113 & 552.503 \\
\hline $\begin{array}{l}\text { População nascida no } \\
\text { estrangeiro }\end{array}$ & 212.996 & 231.652 & 244.096 & 288.879 & 326.376 \\
\hline $\begin{array}{l}\text { Percentagem de população } \\
\text { nascida no estrangeiro }\end{array}$ & $60 \%$ & $56 \%$ & $56 \%$ & $58 \%$ & $59 \%$ \\
\hline $\begin{array}{l}\text { População nascida em portugal } \\
\text { Percentagem de população } \\
\text { nascida em portugal }\end{array}$ & 3.625 & 3.852 & 1.616 & 1.316 & 1.835 \\
\hline $\begin{array}{l}\text { População com nacionalidade } \\
\text { portuguesa }\end{array}$ & $1.02 \%$ & $0.93 \%$ & $0.37 \%$ & $0.26 \%$ & $0.33 \%$ \\
\hline $\begin{array}{l}\text { Percentagem de população com } \\
\text { nacionalidade portuguesa }\end{array}$ & $28.46 \%$ & $27.22 \%$ & $2.02 \%$ & $1.71 \%$ & $0.91 \%$ \\
\hline
\end{tabular}

Fonte: Observatório da emigração português. 2001

${ }^{21}$ Pessoa, Inês Costa. “A comunidade portuguesa em Macau nos anos 80 e 90.” Janus,

${ }^{22}$ Observatório da Emigração. (http://www.observatorioemigracao.secomunidades.pt/np4/ paises.html?id=147, consultado em 2017.01.27) 
Relativamente à divisão por sexo e grupo etário, em 2011, dos 1.835 portugueses nascidos em Portugal e a residir em Macau, 1.105 eram homens e 730 eram mulheres. O grupo etário mais representativo era o dos 40 aos 64 anos, com um peso de 43 por cento no total e com mais homens do que mulheres (62,4\% de homens). Logo a seguir, o grupo com mais peso é o dos 25 aos 39 anos, representando 36 por cento do total. Neste, a distribuição entre homens e mulheres é mais equilibrada (52\% de homens e $48 \%$ de mulheres).

\section{Abordagem metodológica}

O objetivo da investigação foi perceber o que leva os portugueses a Macau e, sempre na perspetiva de destino (daí a designação de imigrantes), conhecer melhor esta comunidade. Porquê Macau? Que alterações se têm dado na história recente da comunidade? Como se integra?

Começámos por definir o guião da entrevista, dividindo-o em três grupos: 1) Informação biográfica e perfil sociodemográfico; 2) Experiência migratória; 3) Perceção de identidade: integração e cultura. A principal vantagem do uso de entrevistas semiestruturadas foi a possibilidade de alterar a ordem das perguntas consoante o entrevistado e algumas não se colocaram porque não faria sentido perguntá-las ou porque foram, entretanto, respondidas no decurso da conversa; o modo como se perguntou variou consoante os entrevistados.

À semelhança do que é feito em estudos qualitativos com recurso ao método de entrevista semidiretiva, a melhor opção foi a amostragem intencional, ou de conveniência, teoricamente sustentada. Este é, portanto, um estudo estatisticamente indicativo, cujo principal objetivo é contribuir para a estruturação de uma base de investigação que permita a realização de outros estudos, quer sobre a mesma comunidade quer sobre outras.

Procurámos contemplar, na construção da amostra, os critérios que julgámos poderem fazer variar o tipo de respostas e encontrar uma diversidade de perfis suficiente para oferecer diversas perspetivas da comunidade. A partir daqui estabelecemos as combinações únicas possíveis de variáveis, de modo a apurar quantas entrevistas seria necessário realizar. Em primeiro lugar, delimitámos o que se entende nesta pesquisa por comunidade portuguesa, o nosso universo de estudo - pessoas nascidas em Portugal que, de facto emigraram para Macau. Pessoas com nacionalidade portuguesa adquirida ainda durante o período de administração portuguesa, mas naturais de Macau, não foram consideradas. Assim, o nosso universo é constituído, tal como referido atrás, por 1.835 portugueses nascidos em Portugal residentes em Macau. 
A nossa amostra foi construída com base neste universo, tendo por base três variáveis: sexo, idade e data de chegada a Macau.

Relativamente à divisão por sexo, optámos por dividir a amostra em 50 por cento homens e 50 por cento mulheres. Como utilizámos o método bola de neve, resolvemos não desprezar hipóteses de entrevistas e, embora não tenhamos utilizado exatamente a mesma proporção do universo ( 60 por cento de homens e 40 por cento de mulheres), julgamos que fazer mais duas entrevistas a homens e menos duas a mulheres não alteraria de forma significativa os resultados.

Quanto à idade, focámo-nos em indivíduos adultos e decidimos não alargar demasiado as faixas, optando por dividir os entrevistados por décadas: inferior a 30 anos, entre 30 e 40 anos, 40 a 50 anos e superior a 50 anos. A definição destas faixas foi feita já depois de iniciado o trabalho de campo (entrevistas). Verificámos que, por exemplo, abaixo dos 20 anos, seria difícil encontrar jovens em que fosse possível cruzar os três critérios, nomeadamente o de chegada antes de 1999 e permanência no território até à atualidade.

Por fim, a última variável foi a data de chegada a Macau. Tendo em conta os dois acontecimentos da história recente que mais marcaram a comunidade portuguesa de Macau - a entrega do território à China, em 1999, e a crise em Portugal - optámos pela divisão em: "chegada antes de 1999", "chegada depois de 1999" e "foi e voltou". Esta última categoria, contempla, sobretudo, pessoas que saíram de Macau por volta de 1999, mas que acabariam por regressar ao território, por razões profissionais e de ligação afetiva ao território.

Considerando então o número de opções por variável - sexo (duas opções), idade (quatro opções), data de chegada (três opções) - chegámos às 24 combinações diferentes possíveis. Para angariação dos entrevistados foi utilizado o método "bola de neve", em que através de um contacto se conseguiram outros. Embora tenhamos construído uma amostra teoricamente sustentada, com perfis únicos, com a utilização deste método, corremos o risco de a amostra ser enviesada, porque os entrevistados podem possuir histórias algo semelhantes, o que é agravado pelo facto de a comunidade ser pequena e de os grupos, ou redes de contacto dentro dela, se intersectarem. As entrevistas foram realizadas em maio e junho de 2013. Foram gravadas em suporte áudio e tiveram a duração média de 49 minutos. 


\title{
1. Percurso migratório
}

\subsection{Macau porque...}

As principais motivações para a escolha de Macau como destino dividem-se em pessoais e profissionais. Entre as motivações pessoais está a reunificação familiar. Neste caso, encontrámos apenas mulheres que o tivessem feito. O companheiro, marido ou namorado já residia ou ia viver em Macau, normalmente por razões profissionais, e a pessoa em causa acompanhou-o. De seguida, a facilidade com que conseguiram encontrar emprego na região, especialmente devido às qualificações, permitiu-lhes permanecer no território.

\begin{abstract}
"Porque casei e a pessoa com quem casei estava cá. Entretanto, arranjei trabalho cá logo passado 15 dias. Na altura não tinha terminado Direito, mas comecei logo a trabalhar numa área relacionada com o Direito. Depois fui a Portugal terminar." (F.C., mulher, 42 anos. Desde 1991 em Macau, saíu em 1999 e regressou em 2002. Jurista.)
\end{abstract}

Entre as razões profissionais, estão o facto de a pessoa já ter tido uma experiência internacional e não desejar regressar a Portugal ou ter obtido uma proposta de trabalho em Macau. Para os imigrantes que trabalhavam em Portugal numa instituição pública, a possibilidade de manterem o cargo em Portugal para quando regressassem foi um aliciante forte, já que lhes deu segurança.

"Não tínhamos nada a perder, porque tínhamos lugar no quadro em Portugal e se viéssemos trabalhar para Macau, o tempo de serviço feito em Macau contava para a carreira de Portugal e quando pretendêssemos voltar para Portugal, teríamos assegurado o nosso lugar no quadro e é uma situação muito confortável.” (E.D., homem, 41 anos. Desde 2003 em Macau. Jurista.)

A crise em Portugal marcou em particular os imigrantes mais recentes. Uns estavam desempregados e procuraram uma oportunidade e outros, mesmo estando empregados, receberam uma proposta mais atraente em Macau, quer em termos de desafio profissional quer relativamente a remuneração. Muitas vezes, as motivações profissionais mesclam-se com as pessoais. Além de ser um desafio profissional, trata-se também de uma oportunidade para conhecer uma nova cultura. Em ambos os casos, a escolha da região pode ter sido por já terem vivido anteriormente ali e, consequentemente, ser um território em que previsivelmente teriam uma maior facilidade de adaptação; por terem amigos 
ou família no território, que lhes facultariam alojamento numa primeira fase; ou por terem sido estes a "abrir-lhes as portas" a uma nova oportunidade profissional.

"Experimentei o que era «não trabalhar» e viver em Portugal e decidi que queria estar cá fora, é a relação com uma cultura totalmente diferente, é estimulante, e também porque em Portugal não conseguia emprego. Portanto, já estava a ser complicado quando eu vim embora, já não estava a conseguir emprego, a expectativa de carreira não era bem aquilo que eu queria, porque era tudo estágios ou contratos de curta duração e não me davam estabilidade e eu estava à procura de uma certa estabilidade, que consegui, mais ou menos, na Ásia.” (B.R., mulher, 27 anos. Desde 2013 em Macau. Gestora de produto.)

Entre os que saíram do território e depois regressaram, há a considerar os que chegaram pela primeira vez após 1999 e os que chegaram antes de 1999 e regressaram após 1999. Nos casos dos imigrantes que chegaram a Macau depois de 1999, as principais razões para uma saída são a saturação ou o cansaço sentidos e o sentimento de claustrofobia que sentiam em Macau. Trata-se de um território com uma pequena dimensão geográfica, em que a comunidade portuguesa, embora tendo crescido nos últimos anos, representa apenas 0,3 por cento da população. O término dos contratos e as saudades de Portugal são outras razões. Depois, após um período fora, as oportunidades profissionais são a principal motivação para o regresso.

"Precisei de sair daqui um bocadinho para «tomar banho», não é, e para me sentir longe de tudo isto e porque é bom sair daqui, porque isto é muito formatador, formata as pessoas, a maneira de agires, de olhares, de reagires, e é doentio nesse sentido." (P.C., homem, 40 anos. Desde 2003 em Macau, saiu em 2008 e voltou em 2013. Jornalista.)

No caso dos imigrantes que chegaram antes de 1999, o principal motivo para a saída foi o handover. O sentimento de instabilidade que se criou no território antes de 1999, mesmo que sem grande fundamento, levou muitos portugueses a regressar a Portugal. Outras das razões foi o facto de muitos dos imigrantes que vieram para Macau antes de 1999 serem ainda crianças na época. Ao terminarem o ensino secundário, optaram por fazer uma licenciatura em Portugal. A crise em Portugal é o principal motivo para um regresso ao território.

"É a segunda vez que estou em Macau, vim para trabalhar. Estive cá entre 1995 e 1999, vim através de um acordo Portugal-China, fui requisitado e vim 
para cá trabalhar. Voltei novamente em 2012, devido à crise que estava iminente em Portugal, respondendo a um convite, que me foi endereçado em 2010/2011 pela Ordem dos Médicos.” (S.G., homem, 59 anos. Desde 1995 em Macau, saiu em 1999 e voltou em 2012. Licenciado em medicina, desempregado.)

\subsection{Quando cheguei a Macau...}

A maioria dos entrevistados não possuía uma ideia clara do que era Macau até desembarcar no território. Os que chegaram antes de 1999 possuíam uma ideia muito remota, construída através dos livros da escola, ou então uma visão quase que romântica de um sítio exótico do Oriente. Com o célebre "caso Melancia" 23 e com a cerimónia de transferência para a China, Macau ganhou mais visibilidade a partir do final dos anos 1990.

"A imagem mais recente que tinha de Macau foi a da transição, porque vi na BBC a cerimónia de transição. Tinha uma imagem da primária $(. .$.$) e mais$ tarde, tinha aquela imagem que foi feita nos anos 90 , de corrupção, do caso Melancia, do fax, da TDM." (P.C., homem, 40 anos. Desde 2003 em Macau, saiu em 2008 e voltou em 2013. Jornalista.)

O conhecimento sobre Macau não se revelou importante entre os entrevistados na sua decisão de imigrarem. Alguns chegaram a Macau sem terem procurado informação e conhecendo praticamente nada sobre a região. Para os que procuraram, uma das principais fontes de informação sobre o território foram os amigos e a família já residentes. No entanto, como salienta A.I., essa imagem, por mais detalhada que possa ser, dificilmente consegue abarcar os pormenores que só quem conhece o território pode perceber.

"Vinha com pequenas ideias, porque falava com o meu pai pelo Skype e ele contava, vinha com algumas ideias, mas, lá está, como eu costumo também dizer aos meus colegas portugueses, uma pessoa pode dar mil e um exemplos de Macau, mas só quem cá está é que consegue reparar em tudo o que Macau envolve" (A.I., homem, 28 anos. Desde 2013 em Macau. Disc Jokey.)

Os cheiros peculiares, os sons, a dinâmica da cidade e o clima são as principais características de Macau, que tiveram um maior ou menor impacto, mais positivo ou mais negativo, na primeira aproximação ao território. Para

${ }^{23}$ Jornal Público, artigo "Supremo põe fim a caso Melancia”, de 2002.10.03 (https://www. publico.pt/2002/10/03/sociedade/noticia/supremo-poe-fim-a-caso-melancia-186751, consultado em 2017.01.29) 
alguns a visão romântica de um Macau exótico desmoronou-se logo à chegada. A proximidade com Portugal quer através da arquitetura quer através do número de portugueses, que antes de 1999 era maior, são outros elementos que marcaram logo no início os entrevistados.

"Vim encontrar uma cidade muito engraçada, porque tinha muitos portugueses (...) Ao mesmo tempo tinha um cheiro muito peculiar, porque não havia ainda os tratamentos que existem hoje, esgotos, recolha de lixo." (F.C., mulher, 42 anos. Desde 1991 em Macau, saiu em 1999 e regressou em 2002. Jurista.)

\section{Integração e (re)construção identitária}

\subsection{Ponte com a família e amigos}

A distância em relação à família no país de origem é sentida, sobretudo, quando algum evento especial acontece e em que não se pode estar presente. S. P. (homem de 42 anos, desde 1994 em Macau e jurista) refere o facto de neste tempo todo nunca ter celebrado o aniversário da mãe presencialmente. A relação que se constrói no dia-a-dia com família e amigos não é possível manter quando se está longe. $O$ receio que alguns imigrantes referem é de que estas relações afetivas não resistam à distância.

"As pessoas com quem me dou ou com quem me dava antes de vir, se, entretanto, tiverem passado dez anos, não deixam de ser amigos, não deixamos de ter alguma cumplicidade, mas faz muita diferença, porque há uma vida diária, sobre aquela notícia naquele jornal, aquele café daquela pastelaria, aquele caixote do lixo que não sei o quê, aquele autocarro não sei que mais. Isso escapa. Essas coisinhas também fazem parte da vida, da partilha entre pessoas, de comunidade, e eu acho que, se viver cá muito tempo, há de haver um corte e eu, outro dia, estava a pensar nisso. Isso é uma coisa que me entristece, porque é quase assustador, porque tenho bons amigos". (G. J., homem, 44 anos. Desde 2007 em Macau, saiu em 2008 e regressou em 2012. Jurista.)

Verificou-se entre os entrevistados que, no que respeita aos afetos, procuram compensar o que perdem com o que ganham. Este balanço foi genericamente positivo. Por exemplo, se não podem estar tantas vezes como gostariam com a família, passam a dar mais valor aos momentos em que podem estar juntos. A solidão que se pode sentir, especialmente no início do processo de adaptação à sociedade de acolhimento, é também compensada pelo crescimento pessoal. 
Quando colocados perante uma situação adversa, os imigrantes aprendem a lidar com ela. O facto de serem obrigados a saírem da zona de conforto afetivo que possuíam no país de origem leva a um processo de aprendizagem só possível nestas condições. É o que refere G. J.:

"Sinto que em Macau, e já não é de agora, aprendi a estar sozinho e a não ter medo da solidão ( ...) ainda que sinta diferença [quando regressar] (...) ainda que não voltemos a estar exatamente no estado em que estávamos, com certeza que continuaremos a ser amigos (...) Os afetos são a coisa mais importante (...) é isso que acho de maravilhoso na vida, e isso é uma das coisas por que não me assusta envelhecer, é que quanto mais velho sou, mais rico sou, porque eu coleciono pessoas." (G.J., homem, 44 anos. Desde 2007 em Macau, saiu em 2008 e regressou em 2012. Jurista.)

\subsection{Relação com Portugal}

"Nós temos sempre uma ligação com Portugal, porque no fim de contas tu estás num café, inevitavelmente falamos de política, do que se passa com o governo, sobre um programa que tenha acontecido, sobre um prémio de um poeta ou porque a Joana Vasconcelos vai expor aqui e acolá. Os portugueses aqui nunca perdem contacto, é impossível." (F.C., mulher, 42 anos. Desde 1991 em Macau, saiu em 1999 e regressou em 2002. Jurista.)

Como faz notar F.C., é difícil perder a ligação a Portugal quando se está em Macau. Porém, por mais que alguns dos imigrantes entrevistados se sintam em Macau quase como se estivessem em Portugal, ao falar do seu país referem elementos ambientais, culturais e afetivos que não são passíveis de ser replicados na região que os acolhe.

Após vários anos de imigração, como acontece no caso de G.D., há 12 anos em Macau, a parte da sua identidade que a liga a Portugal começa a separar-se daquilo que é a sua vida atualmente, fazendo com que sinta ter já duas vidas, uma anterior a Macau e outra que construiu, entretanto.

“Tenho saudades da minha vida lá. Parecem partes da minha vida que está completamente separada, sítios que gostava muito em Portugal, acesso mais fácil a coisas que me identifico, quer locais, coisas tão simples como ir comer uma tosta mista e beber um café, que aqui em Macau não se encontra em cada esquina." (G.D., mulher, 37 anos. Desde 2002 em Macau. Advogada.) 


\subsection{Dinâmica comunitária}

Entre os principais adjetivos utilizados pelos imigrantes entrevistados para caracterizar a sua comunidade estão "fechada" e "pequena".

"As pessoas vêm de fora, muitos estão em Macau, mas continuam a viver como se vivessem em Portugal. Quer dizer que as pessoas se juntam num gueto, comem a mesma comida, têm as mesmas conversas, veem os desafios de futebol, ouvem a mesma música (...) É uma comunidade que vive dentro de si própria, porque a maioria não comunica em cantonês, a maioria não entra no mundo cultural chinês, porque não é fácil (...) A princípio, as pessoas têm vontade e tentam entrar, mas deparam-se com enormes dificuldades e então a solução é esta: em vez de tentar ultrapassar, as pessoas recolhem-se." (A.J., homem, 61 anos. Desde 1959 em Macau, saiu em 1970, regressou em 1982, saiu em 1999 e regressou em 2004. Professor universitário na área de História.)

Como características positivas está o ser "coesa". Em especial nos primeiros tempos de adaptação a Macau, para alguns imigrantes, o facto de ser uma comunidade pequena é até benéfico:

"A comunidade portuguesa, em geral, do meu ponto de vista, é bastante coesa. Dentro dos diferentes grupos que se formam, tentam um bocadinho manter a sua forma de estar na vida, como eu tinha quando estava de volta em Portugal." (A.P., homem, 26 anos. Desde 2012. Gestor de "Food and Beverage" num hotel.)

A comunidade portuguesa sofreu grandes alterações desde 1999 até à atualidade, quer no número de pessoas quer na sua composição. Após a transição grande parte dos imigrantes portugueses regressou a Portugal, o que fez diminuir drasticamente o número de imigrantes no território e, por consequência, o ambiente da comunidade. A partir de 2002, a abertura ao jogo fez aumentar o custo de vida em Macau, que não foi acompanhado pelo aumento dos salários, refletindo-se também nas dinâmicas sociais dos portugueses. Em contrapartida, a melhoria no nível de vida da comunidade chinesa local fez com que também ela passasse a frequentar locais antigamente apenas ocupados por portugueses. Se no período de administração portuguesa existia uma clivagem entre o nível de vida português e o chinês, hoje essas discrepâncias são mais notórias relativamente às comunidades, normalmente de origem asiática, associadas a atividades menos qualificadas, como a comunidade filipina. A possibilidade de exercer um cargo importante e o acesso a um nível de vida que não possuíam 
em Portugal continuaram, ainda depois de 1999, a marcar os comportamentos e sentimentos de alguns imigrantes em relação a outras comunidades.

"Depois também há muitos portugueses que estão aqui e que têm uma atitude autoritária, discriminatória em relação aos filipinos, por exemplo. Há vários tipos de comportamentos dos portugueses aqui em Macau. Tem a ver com a formação das pessoas e da oportunidade que se tem de ter dinheiro e do exercício do poder.” (F. C., mulher, 42 anos. Desde 1991 em Macau, saiu em 1999 e regressou em 2002. Jurista.)

A passagem do governo para mãos chinesas mudou os perfis de qualificações dos imigrantes. Anteriormente a 1999 a comunidade era mais homogénea, com a maioria das pessoas a trabalhar para o governo. A crise económica em Portugal, que se começou a sentir em Macau sensivelmente a partir de 2008, fez com que muitos portugueses regressassem ou escolhessem o território para melhorar as suas condições de vida. Assim, a comunidade está hoje mais diversificada com pessoas a trabalhar em diversas áreas.

“A comunidade portuguesa antes de 1999 estava sobretudo ligada à administração (...) os únicos que trabalhavam na privada eram os advogados. Agora não, temos desde engenheiros, arquitetos, designers, há uma série de áreas onde a comunidade portuguesa se está a expandir." (S. P., homem, 42 anos. Desde 1994 em Macau. Jurista.)

Mas este crescimento cria também divergências dentro da própria comunidade e afeta em particular os imigrantes mais antigos que procuram, eles próprios, redefinir-se quanto a ela.

"Quando eu cheguei a Macau eram só técnicos superiores da administração, quadros superiores, professores ou advogados. Era raro haver outro tipo de pessoas cá, portugueses. Há coisa de dois ou três anos para cá tem vindo outro tipo de emigração. São quadros mais baixos. Por exemplo, eu nunca tinha visto trabalhar num restaurante um empregado de mesa, vindo de Portugal de propósito para ser empregado de restaurante ou de café (...) essas pessoas devem ter um nível de vida que nem os macaenses nem os chineses conseguem perceber, porque nunca tinham visto portugueses a fazer este tipo de tarefas." (E. D., homem, 41 anos. Desde 2003 em Macau. Jurista.)

Os que chegaram há menos tempo, embora percebam que estão a inserir-se numa comunidade em mudança, consideram que esta partiu deles. Foram eles 
que decidiram sair de Portugal. Tudo o que enfrentam em Macau é compensado pela melhoria na sua situação profissional:

“Acho que essa comunidade é um bocadinho fechada, os que já cá estavam. Acho que têm já a sua vida toda muito organizada e acho-os um bocadinho fechados (...) os que chegaram agora estão abertos a tudo, estão abertos a experiências novas, estão abertos a experimentar coisas novas.” (C. M., mulher, 48 anos. Desde 2012 em Macau. Arquiteta.)

Uma falta de identificação com estas características da comunidade faz com que alguns imigrantes procurem uma maior interação com as outras comunidades e com a sociedade local. O desafio está em conseguir ultrapassar as barreiras culturais e linguísticas. É o caso de A. T., que viveu em Macau até aos 12 anos, saiu e regressou aos 28 anos.

"Isto é uma cidade, ainda tem muita população e eu também não estou só com pessoas portuguesas, também tenho amigos chineses, amigos macaenses e às vezes opto por estar com eles, porque estou mais à vontade, não estou sob o olhar de uma pessoa que pode estar a querer observar o meu comportamento e como é que eu faço isto e aquilo, se calhar estou mais à vontade, sinto-me melhor, sinto-me mais em casa." (A. T., homem, 28 anos. Desde 1985 em Macau, saiu em 1996 e voltou em 2012. Licenciado em design, desempregado.)

Por último, estão os imigrantes que dizem não se sentir integrados, como é o caso de P.C. A principal razão para que tal não aconteça é não desejar integrarse; para isto, fornece uma série de características de Macau (de notar, que já não é a primeira vez que vive na região) que o fazem não querer sujeitar-se ou render-se a elas.

"Não me sinto integrado, porque não me quero sentir integrado, porque o que existe aqui... isto são relações de poder que se estabelecem em Macau, muito fortes e muito violentas, em que o dinheiro comanda a vida. Apesar de ser um país dois sistemas, apesar do que está escrito na lei, aqui, quem tem dinheiro pode ser rei, quem não tem, não é. $E$ depois não me sinto integrado (...) as pessoas fazem concessões porque têm de viver aqui (...) em termos de carácter, em termos profissionais, familiares e, portanto, todas as relações sociais são condicionadas por essas relações de poder." (P. C., homem, 40 anos. Desde 2003 em Macau, saiu em 2008 e voltou em 2013. Jornalista.) 
Para A. M., mais do que uma dificuldade na adaptação a Macau, não existe a vontade de um envolvimento mais profundo quer com a comunidade portuguesa quer com a sociedade em geral. Como escape a esta restrição à comunidade portuguesa e a uma falta de identificação com Macau em geral, A. M. procura relacionar-se com chineses na China continental (Zhuhai):

"Eu tive uma adaptação que não foi difícil, embora convenhamos que viver em Macau, especialmente quando se vive sozinho, não é fácil (...) porque as pessoas que vêm para Macau têm um certo perfil (...) muitas pessoas vêm com um problema qualquer e pensam vir resolvê-lo para Macau (...) este isolamento e este grupo restrito de pessoas falantes de português, aí vão complicar as coisas, logo o contacto com as pessoas não é fácil. Agora eu tenho mais é contactado com pessoas da China (...) cada vez estou mais na China do que aqui." (A. M., homem, 55 anos. Desde 2009 em Macau. Médico.)

A maioria dos imigrantes entrevistados procura manter em Macau hábitos culturais que tinha no país de origem. Algumas das festas populares que existem em Portugal são realizadas numa menor dimensão. Um dos exemplos é a festa de São João, realizada no Bairro de São Lázaro, um dos mais antigos de Macau.

"Os Santos Populares ontem. Hoje foi conversa na hora do café lá no emprego, falar dos Santos Populares, a sardinha assada e o cheiro da sardinha assada. São pequeninas coisas que têm a ver connosco e com as nossas raízes." (P. A., mulher, 48 anos. Desde 1993 em Macau. Economista.)

A presença portuguesa durante quase 500 anos faz com que muitos elementos culturais portugueses tenham sido replicados em Macau. Desde os edifícios e das placas com o nome das ruas ou indicações até ao nome dos restaurantes e das lojas, tudo está escrito em português e chinês. Também o facto de a língua portuguesa ser uma das línguas oficiais faz com que seja possível falar apenas português nas instituições públicas. Tudo isto, como referem alguns dos imigrantes entrevistados, permite que vivam em Macau como se estivessem em Portugal.

"Acho que essa é a grande mais-valia de se estar em Macau, porque estando tão longe de Portugal, consegue-se viver um bocadinho de Portugal aqui, verdadeiramente, porque conseguimos estar a falar em português, a ler português, a comer português, a beber português." (A. D., mulher, 31 anos. Desde 2013 em Macau. Jurista.) 
Ainda assim, alguns dos hábitos vão sendo perdidos, porque não é possível mantê-los em Macau. A tentativa de continuar a viver em Macau como se estivessem em Portugal, ao contrário de ser uma forma de facilitar a vida fora do país de origem, para alguns dos imigrantes, só torna a adaptação mais difícil. É o que explica também C. J.:

"Sinto que há um natural distanciamento, porque se a pessoa tentar manter uma grande colagem ou proximidade com a cultura portuguesa, depois morre de saudades e, portanto, para própria sobrevivência, há um distanciamento que se cria, que tentamos nutrir. Isso não tem que ver com uma falta de solidariedade com o que se passe lá." (C. J., mulher, 30 anos. Desde 1983 em Macau, saiu em 2000 e regressou em 2004. Advogada.)

\subsection{Regresso a Portugal}

Os desejos dividem-se quando se fala de um regresso a Portugal, mas em todos os casos o horizonte temporal é indefinido. Existem os imigrantes que, sem qualquer hesitação, dizem pretender voltar, mesmo que gostem de viver em Macau e já residam no território há vários anos. Os entrevistados com menos de 30 anos, que chegaram há pouco tempo à região, mesmo que pretendam regressar para estabelecerem a sua vida familiar em Portugal, querem primeiro progredir profissionalmente e experimentar também outros países. O regresso à Europa é uma das alternativas a um regresso a Portugal, tendo como vantagem a proximidade ao país de origem.

"Eu sinto que gostava de voltar a Portugal pelo país e pelas pessoas que lá estão. Em termos profissionais é mais complicado, mas não fecho a porta a ir para um país que esteja mais próximo de Portugal ou que tenha uma cultura mais aproximada à de Portugal. Eu quero voltar a Portugal, mas não sei quando. Não me importo de continuar a ser imigrante noutro país qualquer europeu." (O. J., homem, 30 anos. Desde 2010 em Macau. Advogado.)

São sobretudo os que vivem há mais tempo em Macau, que constituíram família no território ou que ali criaram raízes, quem não faz planos a curto ou a longo prazo de regresso a Portugal. Para os mais velhos, com mais de 50 anos, Macau representa uma oportunidade de continuarem a exercer as suas profissões. Alguns veem mesmo Portugal como um país que não lhes oferece quaisquer condições de trabalho, pelo que não têm intenção de regressar. 
"[Regressar a Portugal] de férias sim, [em definitivo] não. Eu agora estou aqui, amanhã posso estar na China, sei lá, em África... agora, eu sei que em Portugal não se pode trabalhar, porque eu trabalho em Portugal para pagar impostos, e eu estou farto de pagar impostos e as pessoas cada vez querem mais, em inglês, os chamados entitlements, direitos, direito a isto, direito àquilo, basta-me ligar a televisão, fico logo maldisposto, têm direito àquilo com os meus impostos! Eu não quero mais, já chega!” (A. M., homem, 55 anos. Desde 2009 em Macau. Médico.)

As ligações que estabeleceram com Macau a par das que mantêm com Portugal fazem com que, para alguns, o ideal fosse viver uma parte do tempo num lado e o resto no outro. A solução para o seu dilema estaria precisamente em conseguir esse equilíbrio, o que não é fácil devido às questões profissionais.

"Não, eu quando volto, quer dizer, a ideia é a base ser aqui. A base não é lá, a base é cá. Eu gosto que a base seja cá, isto é um bom sítio geograficamente falando para te movimentares para outros sítios. A nível de qualidade de vida consegue ser melhor, consegues ganhar mais dinheiro, que te permite fazer uma vida cá e lá. Vivendo lá, não conseguia vir cá.” (S. M., mulher, 26 anos. Desde 2004 em Macau, saiu em 2010 e regressou em 2012. Gestora de conteúdos.)

\subsection{Integração na sociedade de acolhimento}

$\mathrm{Na}$ adaptação à sociedade de acolhimento há a considerar a relação que o imigrante estabelece com a sua própria comunidade e a forma como a vê, o nós; mas também a forma como vê a sociedade de acolhimento, quer o país ou a região quer os residentes locais, os outros.

A partir de 2002, o impacto do crescimento descontrolado do número de casinos tem vindo a destruir as características arquitetónicas de Macau e a fazer aumentar o número de pessoas que circulam na região, não só visitantes, mas também residentes. $\mathrm{O}$ tráfego aumentou e o comércio tradicional tem sido substituído por grandes cadeias de lojas.

"Hoje Macau está a ser tomado por cadeias e não por negócios individuais, os negócios, o pequeno comércio, individual, familiar, tudo isso tem vindo a ser tragado pela força do dinheiro." (A. N., mulher, 68 anos. Desde $1982 \mathrm{em}$ Macau. Advogada.) 
As ilhas da Taipa e de Coloane, tantas vezes descritas nos livros de Enrique de Senna Fernandes ${ }^{24}$, também se alteraram radicalmente. Hoje a Taipa é essencialmente constituída por prédios, mantendo-se apenas o bairro da Taipa Velha, com as casas-museu, onde se pode vislumbrar o que seria Macau há umas décadas. Entre a Taipa e Coloane foi construído um aterro (Cotai), onde existem agora casinos e hotéis. Mesmo em Coloane, onde ainda se conserva alguma natureza, as diferenças são visíveis mesmo para os que não residem no território há muito tempo, com a construção de bairros para a designada "habitação económica". Constituídos por prédios gigantescos, estes bairros vieram descaracterizar uma ilha que já foi um pequeno paraíso para os residentes de Macau.

"É claustrofóbico, uma pessoa dá três voltas e está no mesmo sítio. Eu comparo Macau a uma ilha. Sempre ouvi dizer que os ilhéus têm a síndrome da insularidade, eu tenho síndrome da insularidade em Macau." (C. P., mulher, 53 anos. Desde 1999 em Macau. Jurista e professora universitária.)

A especulação imobiliária é outro dos problemas mais apontados. Especialmente para os imigrantes que não trabalham na função pública e que, deste modo, não têm direito a uma casa atribuída pelo governo, a procura de habitação é um verdadeiro "quebra-cabeças". As casas são arrendadas a valores altos, que sobem, no mínimo, a cada dois anos, período de duração mais normal para cada contrato.

"A especulação está descontrolada. Os preços das casas, os arrendamentos também. As pessoas, coisa que a comunidade portuguesa se queixa também, andam com a casa às costas ao fim de dois anos. Não se fazem arrendamentos suficientemente longos e as pessoas, ao fim de dois anos, vão para o meio da rua, porque a renda que o senhorio lhes propõe é elevada." (S. H., homem, 56 anos. Desde 1982 em Macau. Advogado.)

Entre os principais problemas de Macau, A. N., que reside no território desde os anos 1980, acrescenta a inexistência de uma classe média, com reflexos a vários níveis, nomeadamente na falta de uma massa crítica intelectual e na impreparação técnica dos quadros. Isso abre, no entanto, oportunidades aos imigrantes portugueses, que vêm colmatar essas lacunas.

24 Entre os seus livros mais conhecidos encontram-se "Amor e dedinhos de Pé" e os "Os Dores". Ambos descrevem uma Macau anterior aos anos 1950, com estórias que permitem entender um pouco como era a sociedade macaense. 
“Os ricos estão bem, cada vez melhor, a classe média cresce muito pouco e ai é o grande problema de Macau, porque nesta medida não lhe cresce massa crítica, gente com preparação técnica, com um grau de cultura que leve a cidade a desenvolver certos aspetos da vida artística, social, etc." (A. N., mulher, 68 anos. Desde 1982 em Macau. Advogada.)

Atualmente, compreender a organização social de Macau não é simples. Como vimos atrás, nos anos 90, Pina Cabral (1994) identificava quatro grupos: os portugueses, os macaenses, os chineses e os outros. "Chinês", "português" ou "macaense" continuam a não ser conceitos óbvios e ainda existe alguma discussão em relação à sua definição. Na nossa pesquisa, quer através da observação feita no terreno quer pelas entrevistas, verificamos que, quando se fala em "chinês", há hoje que distinguir entre chinês de Macau, alguém que partilha os valores culturais da região e que fala cantonês, e chinês continental, que possui uma outra cultura, a da sua região de origem, e que poderá ter como língua materna o mandarim ou um dialeto.

Alguém pode declarar-se português porque tem a nacionalidade portuguesa, mas pode ter pais chineses, ter nascido em Macau, nunca ter estado em Portugal e não falar português. Simplesmente adquiriu a nacionalidade por ter nascido num território que foi administrado por Portugal.

O conceito de "macaense" é o mais complexo. Se, para alguns, ser "macaense" significa simplesmente ter nascido em Macau, para outros, o conceito de "macaense" só se aplica a quem tenha origem numa família com história e tradição na região e que resulte de um cruzamento entre portugueses ou luso-descendentes e asiáticos. Por exemplo, alguém nascido atualmente na região, que não pertença a uma destas famílias, mas que seja resultado de um cruzamento entre alguém chinês e alguém português, pode ser considerado português ou chinês, consoante opte por uma das nacionalidades, mas não "macaense". A noção de "comunidade macaense" tem origens profundas no tempo e que remontam ao passado colonial português.

"O aumento das comunidades crioulas, sobretudo nas Américas, mas também em zonas de África e da Ásia, conduziu inevitavelmente ao aparecimento de euro-asiáticos, euro-africanos e euro-americanos, não como curiosidades de ocasião, mas como grupos sociais visíveis. A sua emergência permitiu o florescimento de um modo de pensamento que prefigurava o racismo moderno. O caso de Portugal, o primeiro dos conquistadores europeus do mundo, ilustra bem este aspeto. Na última década do século XV, D. Manuel I conseguiu ainda «resolver» a sua «questão judaica» pela conversão forçada em larga escala (...) Menos de um século mais tarde, contudo, vemos Alexandre 
Valignano, o grande reorganizador da missão jesuíta na Ásia entre 1574 e 1606, opor-se veementemente à admissão de indianos e euro-indianos como

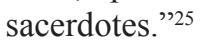

À medida que os europeus iam chegando e permanecendo noutros continentes foram-se criando comunidades crioulas, que levaram não só ao surgimento de euro-asiáticos, mas também de euro-africanos e de euro-americanos. A existência da comunidade luso-asiática de Macau é, neste sentido, surpreendente porque - ao contrário do que aconteceu em algumas colónias portuguesas em que toda a população se miscigenou, como por exemplo no Brasil - a "comunidade macaense" manteve-se como um resquício histórico. Conseguiu chegar aos nossos dias conservando algumas das suas particularidades: um dialeto próprio, o patuá, ainda que em vias de extinção, e hábitos culturais específicos que resultam das suas influências portuguesas e chinesas ${ }^{26}$.

Embora poucos entrevistados tenham contacto próximo com esta comunidade, para A. J., historiador, a importância da comunidade é grande, pois é parte do património identitário de Macau.

"Temos uma comunidade macaense, que é muito importante, e que faz parte da comunidade cultural de Macau. É uma comunidade que comunga dos aspetos culturais de Portugal, mas também dos aspetos culturais da China, de Macau, da cultura de Macau, que no fundo é uma cultura chinesa. Tem um lado chinês muito forte (...) fala o português, fala o chinês, sobretudo os mais velhos. Já há muitos jovens, sobretudo depois de 1999, que deixaram de aprender e já não falam português. Embora nesta comunidade um grande número esteja na diáspora.” (A. J., homem, 61 anos. Desde 1959 em Macau, saiu em 1970, regressou em 1982, saiu em 1999 e regressou em 2004. Professor universitário na área de História.)

Os imigrantes que se consideram portugueses, mas não estrangeiros em Macau, identificam-se como pessoas de Macau. Ser pessoa de Macau é sentir que se pertence a Macau e essa sensação de pertença surge, por um lado, de um sentido de dever, de responsabilidade cívica com Macau, de não estranhar os costumes de Macau e, mais do que isso, de se identificar mesmo com eles. Por outro lado, surge, simultaneamente, dos direitos que Macau confere aos portugueses exatamente por serem portugueses. Este sentimento de pertença,

${ }^{25}$ Benedict Anderson, Comunidades Imaginadas. Reflexões Sobre a Origem e a Expansão do Nacionalismo, Lisboa, Edições 70, 2005, p.90.

${ }^{26}$ Isabel Maria Pinto, A Comunidade Macaense em Portugal, Almedina e Instituto Cultural do Governo da RAEM, 2011. 
de envolvimento pela sociedade e, ao mesmo tempo, de reconhecimento, fazem de Macau uma sociedade culturalmente diversa, mas coesa nessa diversidade. As marcas dos portugueses em Macau ocorrem a todo o momento num modo de viver português, que abrange valores europeus e humanistas, e que foram consagrados na Lei Básica de Macau.

\begin{abstract}
"Sabe por que é que eu não me sinto estrangeiro? Porque eu acho que as pessoas olham para mim e vendo que eu sou português também não me sentem estrangeiro, quer dizer, é «aquele quisto que a gente aqui tem não sei há quantos séculos»»". (S. H., homem, 56 anos. Desde 1982 em Macau. Advogado.)
\end{abstract}

\title{
Considerações finais
}

Em todos os imigrantes existe um interesse tanto na manutenção da sua cultura original como nas interações diárias com outros grupos; desejam manter um certo grau de integridade cultural, enquanto procuram participar como parte integrante da rede social mais abrangente. A transição necessária, a alteração de comportamentos no repertório de cada um, que envolve tanto o abandono de alguns elementos da sua cultura como a aprendizagem de elementos de outras, não acontece para todos da mesma forma. O grau de manutenção cultural ou de incorporação de elementos culturais existentes na sociedade de acolhimento dita o grau de integração.

Em Macau, pelo facto de a região ter sido administrada por Portugal até muito recentemente, a forma de vida adotada pelos portugueses no território durante o período de administração portuguesa e que procurava ser feita à imagem do que acontecia em Portugal, ainda pode ser mantida em muitas áreas, que vão desde as leis, à utilização do português no funcionalismo público, às tabuletas com indicações em português que se veem no território. A par disto, o poder económico que os elementos desta comunidade conseguem ainda alcançar por trabalharem em Macau permite-lhes, se quiserem, viajar para países onde podem ter mais contacto com elementos da cultura ocidental ou mesmo para Portugal. Alguns dos imigrantes regressam ao país de origem, pelo menos, uma vez por ano.

Trata-se de uma comunidade muito pequena, que perdeu muito membros após 1999, mas que tem vindo a aumentar nos últimos anos. A ida para Macau de muitos portugueses que não pertencem às áreas tradicionais de inserção profissional - funcionalismo público e advocacia - tem-se refletido na identidade da comunidade como um todo. Está a diversificar-se cada vez mais. A própria sociedade de acolhimento tem passado, desde 1999, por transformações que 
resultam da nova conjuntura da região - que passou de um governo português a um governo chinês e que liberalizou o negócio do jogo em 2002. Qual a identidade que possui Macau hoje? Cidade do jogo ou plataforma de ligação da China ao mundo lusófono?

A comunidade portuguesa tenta hoje uma nova maneira de estar na sociedade local, visando uma maior integração. É um pilar identitário de Macau e, simultaneamente, a sua identidade tem como fundamento o seu papel histórico no território. $\mathrm{O}$ seu papel está ligado à própria manutenção identitária da região, por sua vez ligada a um passado português de onde ainda emanam valores e costumes ligados a essa forma de vida. 